И. А. Слободняк

Байкальский государственный университет, г. Иркутск, Российская Федерация

Д. А. Алексеев

Байкальский государственный университет, 2. Иркутск, Российская Федерация

\title{
ВЛИЯНИЕ РЕЗУЛЬТАТОВ ПЕРЕОЦЕНКИ ОСНОВНЫХ СРЕДСТВ НА ВЕЛИЧИНУ ФИНАНСОВЫХ КОЭФФИЦИЕНТОВ
}

\begin{abstract}
АНнотАция. Вопросы переоценки основных средств подробно освещены в работах по бухгалтерскому учету. Разработана методика проведения переоценки, доказана ее значимость для представления пользователю информации, используемой им при принятии управленческих решений. В то же время в литературе практически не раскрыта методика экономического анализа результатов переоценки, не рассматривается влияние переоценки на показатели финансового состояния. В статье дается краткая характеристика методики проведения переоценки основных средств в соответствии с требованиями российских стандартов бухгалтерского учета и международных стандартов финансовой отчетности. Анализируются требования Налогового кодекса, регулирующие признание результатов переоценки для целей налогообложения прибыли и для целей расчета налога на имущество организаций. Проводится систематизация коэффициентов, характеризующих финансовое состояние, в зависимости от влияния на их величину результатов переоценки. Рассматривается влияние переоценки основных средств на сдвиг точки безубыточности. Предлагается порядок определения величины сдвига (темпа роста) порога безубыточного функционирования.
\end{abstract}

кЛючЕВЫЕ словА. Финансовый анализ; основные средства; переоценка основных средств; точка безубыточности.

ИНФОРМАЦИЯ О СТАТЬЕ. Дата поступления 2 марта 2017 г.; дата принятия к печати 23 марта 2017 г.; дата онлайн-размещения 31 марта 2017 г.

I. A. Slobodnyak Baikal State University, Irkutsk, Russian Federation

D. A. Alekseyev

Baikal State University, Irkutsk, Russian Federation

\section{INFLUENCE OF RESULTS OF REVALUATING FIXED ASSETS BY VALUE OF FINANCIAL RATIOS}

\begin{abstract}
The issues of revaluating fixed assets are highlighted in detail in works on accounting They have developed the methods of implementing revaluations, prove its significance for presenting the information to the utilizer who uses it in making managerial decisions. At the same time, the literature does not practically reveal methods of economic analysis of revaluation results, does not examine the influence of revaluation on the indicators of the financial state. The article gives a brief characteristic of revaluating fixes assets in accordance with requirements of Russian accounting standards and international standards of financial reports. It analyzes the requirements of the Tax Code that regulate recognition of revaluation results both in profit taxation and in calculation of business property tax. It carries out systematization of ratios that characterize the financial state depending on the influence of the revaluation results on their value. It examines the influence of the fixed asset revaluation on the shift of the breakeven point. It offers the order of determining the shift value (rate of growth) of the breakeven functioning threshold.
\end{abstract}

\section{Baikal Research Journal}


KEYWORDS. Financial analysis; fixed assets; revaluation of fixed assets; break-even point. ARTICLE INFO. Received March 2, 2017; accepted March 23, 2017; available online March 31, 2017.

В связи с переходом на составление финансовой отчетности в соответствии с требованиями МСФО, вопросы переоценки внеоборотных активов организации постоянно оказываются в центре внимания специалистов различных областей. Достаточно активно обсуждается методика проведения переоценки, ведется дискуссия относительно необходимости осуществления соответствующих процедур, наконец, об отражении результатов переоценки в учете и отчетности. Однако практически отсутствуют публикации, в которых бы рассматривалось влияние переоценки на основные параметры финансового состояния организации. Фактически декларируется определенная цель: например, сделать информацию бухгалтерской отчетности более достоверной, а переоценка рассматривается как инструмент достижения этой цели. При этом априори считается, что информация о справедливой стоимости активов и обязательств является более достоверной, а соответственно и более полезной для пользователя, чем информация об исторической стоимости элементов бухгалтерской отчетности.

В данной работе мы намеренно не будем вступать в дискуссию о преимуществах оценки по справедливой стоимости. Это тема для другого более масштабного исследования. Здесь же заметим, что, обеспечивая достижение какой-либо цели, необходимо учитывать не только конечный результат деятельности, обеспечившей ее достижение, но и изменение состояния многочисленных иных параметров системы, на которую осуществлялось соответствующее воздействие. Например, очевидно, что изменение в результате переоценки значений сразу нескольких элементов различных форм бухгалтерской отчетности обязательно скажется на результатах оценки финансового состояния организации.

Для определения направления изменений, вызванных проведением переоценки, коротко остановимся на ее методике. В РФ в соответствии с правилами, установленными ПБУ 6/01, коммерческая организация имеет право не чаще одного раза в год (на конец отчетного года) переоценивать группы однородных объектов основных средств по текущей (восстановительной) стоимости. При этом переоценка производится путем пересчета его первоначальной стоимости или текущей (восстановительной) стоимости, если данный объект переоценивался ранее, и суммы амортизации, начисленной за все время использования объекта. Сумма дооценки объекта основных средств в результате переоценки зачисляется в добавочный капитал организации. Сумма дооценки объекта основных средств, равная сумме уценки его, проведенной в предыдущие отчетные периоды и отнесенной на финансовый результат в качестве прочих расходов, зачисляется в финансовый результат в качестве прочих доходов.

Сумма уценки объекта основных средств в результате переоценки относится на финансовый результат в качестве прочих расходов. Наконец, сумма уценки объекта основных средств относится в уменьшение добавочного капитала организации, образованного за счет сумм дооценки этого объекта, проведенной в предыдущие отчетные периоды.

Важным является и то, что суммы, отнесенные в состав добавочного капитала в результате проведенной переоценки объекта, не остаются там навсегда. При выбытии объекта основных средств сумма его дооценки переносится из суммы добавочного капитала организации в состав нераспределенной прибыли организации. В результате, ровно на ту величину, на которую при переоценке была увеличена остаточная стоимость объекта, и соответственно затем увеличена амортизация,

\section{Baikal Research Journal}

электронный научный журнал Байкальского государственного университета 
будет увеличена при выбытии объекта и нераспределенная прибыль хозяйствующего субъекта.

Правила проведения переоценки основных средств согласно МСФО, в целом, аналогичны правилам проведения переоценки согласно российским стандартам бухгалтерского учета (в том числе и в части признания и отражения результатов переоценки с их делением на добавочный капитал (резерв переоценки в соответствии с требованиями МСФО) и нераспределенную прибыль). Однако результат проведения переоценки затем может списываться на нераспределенную прибыль как единовременно при прекращении признания объекта, так и постепенно по мере начисления амортизации.

Что касается проведения переоценки для целей налогового учета, то в рамках данной подсистемы при определении восстановительной стоимости амортизируемых основных средств учитывается переоценка основных средств, осуществленная по решению налогоплательщика только по состоянию на 1 января 2002 г. При этом указанная переоценка принимается в целях налогообложения в размере, не превышающем 30 \% от восстановительной стоимости соответствующих объектов основных средств, отраженных в бухгалтерском учете налогоплательщика по состоянию на 1 января 2001 г. (с учетом переоценки по состоянию на 1 января 2001 г., произведенной по решению налогоплательщика и отраженной в бухгалтерском учете в 2001 г.). При этом величина переоценки (уценки) по состоянию на 1 января 2002 г., отраженной налогоплательщиком в 2002 г., не признается доходом (расходом) налогоплательщика в целях налогообложения. В аналогичном порядке принимается в целях налогообложения соответствующая переоценка сумм амортизации.

При проведении налогоплательщиком в последующих периодах после вступления в силу гл. 25 Налогового кодекса переоценки стоимости объектов основных средств положительная (отрицательная) сумма такой переоценки не признается доходом (расходом), учитываемым для целей налогообложения, и не принимается при определении восстановительной стоимости амортизируемого имущества и при начислении амортизации, учитываемым для целей налогообложения.

Таким образом, фактически можно констатировать, что для целей налогового учета не разрешается амортизация результатов переоценки основных средств, проведенных после 1 января 2002 г., т. е. после вступления в силу гл. 25 Налогового кодекса.

Также необходимо отметить, что если для целей налога на прибыль результаты переоценки, проведенной после 2002 г., не признаются, то для целей налога на имущество результаты проводимых переоценок будут признаваться. Ведь расчет налогооблагаемых баз при исчислении налога на имущество осуществляется исходя из среднегодовой стоимости объектов, определенной в соответствии с правилами бухгалтерского финансового учета, то есть предусмотренными ПБУ 6/01 (за исключением объектов, облагаемых налогом на имущество исходя из кадастровой стоимости).

Полагаем, что это не самый справедливый подход по отношению к налогоплательщику, который существенно снижает стимулы к проведению переоценки. Естественно, что если на размер одного налога - налога на прибыль, процедура переоценки не оказывает влияния, а другой налог - налог на имущество в результате ее проведения возрастет (поскольку в современных российских условиях имеет смысл говорить, как правило, о дооценке основного средства), то конечно это не создает стимулов для осуществления соответствующих процедур.

И еще одно замечание о влиянии результатов переоценки на величину налога на прибыль. Результаты дооценки основного средства, отраженные в бухгалтерском финансовом учете, никак не влияют не только на расчет налога на прибыль

\section{Baikal Research Journal}


текущего периода. При этом они также не учитываются и при продаже этого основного средства, в частности, при определении остаточной стоимости. Такой вывод содержится в письме Минфина от 5 февраля 2013 г. № 03-03-06/1/2474.

Поскольку результаты переоценки (и уценки, и дооценки) основных средств признаются в финансовом учете, но не признаются в налоговом учете, то в учете у организаций возникает постоянная разница, приводящая к формированию постоянного налогового актива или постоянного налогового обязательства.

Достаточно часто после реформирования содержания бухгалтерской отчетности российских организаций у пользователей возникают проблемы с интерпретацией информации о состоянии основных средств в случае проведения переоценки объектов. И если ранее в бухгалтерском балансе приводились данные по состоянию на 1 января и 31 декабря отчетного года, то теперь в указанной форме отчетности отражаются суммы лишь по состоянию на 31 декабря, но в динамике за более длительный период времени. Однако эта ситуация привела к тому, что результат переоценки бухгалтеры вынуждены отражать теперь также по состоянию на 31 декабря (соответствующие изменения были внесены и в ПБУ 6/01), однако пользователю после этого бывает достаточно трудно установить причины увеличения стоимости основных средств в бухгалтерском балансе: то ли имела место ситуация, при которой действительно была расширена имущественная база организации, то ли увеличение остаточной стоимости произошло просто в результате проведенной переоценки.

Для получения дополнительной информации пользователю можно рекомендовать изучение связанной статьи пассива бухгалтерского баланса «Переоценка внеоборотных активов», что позволит определить причины изменения балансовой стоимости основных средств. Ведь движение сумм по статье «Переоценка внеоборотных активов» как раз и доказывает факт проведенной переоценки объектов.

В любом случае оценка показателей по строке «Основные средства» на 31 декабря предыдущего года и на 31 декабря года, предшествующего предыдущему, переносятся из Бухгалтерского баланса за предыдущий год. При этом они не подлежат изменению даже в том случае, если в отчетном году была проведена переоценка основных средств. Ведь в соответствии с правилами бухгалтерского финансового учета сравнительные показатели, приводимые в отдельных формах подлежат корректировке только в том случае, если в отчетном году организация исправляла существенные ошибки, в данном случае в учете основных средств, допущенные в прошлые годы и выявленные после утверждения бухгалтерской отчетности за предшествующий отчетный год (а, следовательно, данные ошибки должны быть исправлены путем ретроспективного пересчета соответствующих статей отчетности за периоды, на которые они оказывали влияние), а также, если в отчетном году имело место изменение учетной политики организации (в данном случае, также по операциям, связанным с основными средствами). Соответствующие положения отражены в ПБУ $22 / 2010$ (в части ошибок) и ПБУ 1/2008 (в части учетной политики). Во всех других случаях сравнительная информация по строке «Основные средства» не пересчитывается. Данной позиции придерживается и Минфин, который в письме от 29 января 2014 г. № 07-04-18/01 указал, что в случае проведения переоценок сравнительные данные за период, предшествующий отчетному периоду, не изменяются.

Итак, в результате проведения переоценки изменяются значения статьи бухгалтерского баланса «Основные средства» или «Нематериальные активы», а также связанной статьи "Переоценка внеоборотных активов» (все-таки в большинстве случае будет иметь место дооценка активов, а не их уценка). Естественно, что такая ситуация может оказать влияние на основные параметры финансового

\section{Baikal Research Journal}

электронный научный журнал Байкальского государственного университета 
состояния организации. При этом существует достаточно большое количество финансовых коэффициентов, при расчете которых используются значения указанных выше статей отчетности:

1. Коэффициент финансового риска [1, с. 42] или коэффициент финансовой активности) [2, с. 228]:

$$
K_{\text {финансового риска }}=\frac{\text { Заемный капитал }}{\text { Собственный капитал }} \text {. }
$$

2. Коэффициент соотношения совокупного капитала к заемному [1, с. 42]:

$$
K_{\text {совокупного капиталак заемному }}=\frac{\text { Валюта баланса }}{\text { Заелньй капитал }} .
$$

3. Коэффициент автономии (финансовой независимости) [2, с. 227; 3, с. 78]:

$$
K_{\text {автономии }}=\frac{\text { Собственныцй капитал }}{\text { Валюта баланса }} \text { бала }
$$

4. Коэффициент обеспеченности собственными оборотными средствами [2, с. $229 ; 3$, с. 78$]$ :

$$
K_{\text {обеспеченности Сос }}=\frac{\text { Собственный капитал }- \text { Внеоборотные активы }}{\text { Оборотные активы }} \text {. }
$$

5. Коэффициент маневренности [2, с. 229]:

$$
K_{\text {маневренности }}=\frac{\text { Собственный капитал-Внеоборотные активьь }}{\text { Собственный капитал }} \text {. }
$$

6. Коэффициент рентабельности собственного капитала [2, с. 229; 4, с. 16; 5, c. $6 ; 6$, с. 22$]$ :

$$
R O E=\frac{\text { Чистая прибьль }}{\text { Среднегодовая стоилость собственного капитала }} \cdot 100 \% \text {. }
$$

7. Доля иммобилизованного капитала в общей величине капитала [1, с. 42; 3, с. 78]:

$$
K_{\text {иммобилизованного капитала }}=\frac{\text { Внеоборотные активы }}{\text { Валюта баланса }} .
$$

8. Коэффициент амортизации [7, с. 122; 8, с. 25] или коэффициент износа основных средств:

$$
K_{\text {амортизаци }}=\frac{\text { Накопленная алортизация }}{\text { Первоначальная стоилость основных средств }} \text {. }
$$

9. Фондооснащенность [8, с. 23]:

$$
\text { Фондооснащенность }=\frac{\text { Остаточная стоилость основных средств }}{\text { Производственная площадь }} \text {. }
$$

10. Фондовооруженность [Там же]:

$$
\text { Фондовооруженность }=\frac{\text { Остаточная стоилость основных средств }}{\text { Среднегодовая численность работников }} \text {. }
$$

11. Фондоотдача [8, с. $26 ; 9$, с. 58]:

Фондоотдача $=\frac{\text { Вьцучка }}{\text { Среднегодовая остаточная стоилость основных средств }}$.

\section{Baikal Research Journal}


12. Чистые активы [10, с. 219-220; 11, с. 2-3]:

Чистые активы = Активы, принилаелые к расчеты-

-Пассивы, принилаелье к расчету.

13. Собственный оборотный капитал [4, с. 15] или собственные оборотные средств [12, с. 62]:

\section{Собственный оборотный капитал= = Собственный капитал-Внеоборотные активы.}

Зная порядок расчета указанных выше финансовых коэффициентов, можно предположить, как результат переоценки основных средств повлияет на ту или иную характеристику финансового состояния. При этом можно воспользоваться методикой Ю. В. Гильдеевой и И. А. Слободняка [13, с. 14-18], в соответствии с которой все показатели, характеризующие финансовое состояние хозяйствующего субъекта, значение которых будет изменяться в результате проведенной переоценки основных средств, можно подразделить на несколько групп:

1. Финансовые коэффициенты, при расчете которых $\Delta-$ изменение статьи бухгалтерской отчетности в результате переоценки, - аддитивно присутствует и в числителе, и в знаменателе дроби. В общем виде расчет коэффициентов данной группы после проведения переоценки выглядит следующим образом:

$$
K_{1 \imath p}=\frac{a+\Delta}{b+\Delta} .
$$

В состав показателей данной группы можно включить коэффициент автономии, долю иммобилизованного капитала в общей величине капитала. Очевидно, что поскольку все указанные коэффициенты $<1$, то в результате проведения дооценки основных средств их значение увеличится, а при проведении уценки уменьшится.

Следовательно, если говорить об экономическом смысле данного увеличения, то подобная корректировка сформирует улучшенное представление о финансовой устойчивости организации.

Если же значение какого-либо из коэффициентов изначально было > 1 (таким может быть, например, значение коэффициента достаточности собственного капитала для формирования внеоборотных активов, в случае когда собственный капитал превышает внеоборотные активы), то в результате проведения дооценки значение коэффициента будет снижаться, а в результате уценки - возрастать.

При этом если:

$$
K=\frac{a}{b} \text { и } K^{\prime}=\frac{a+\Delta}{b+\Delta},
$$

то тогда имеем, что темп роста коэффициента в результате проведенной операции по трансформации составит:

$$
T_{\text {роста K }}=\frac{K^{\prime}}{K}=\frac{(a+\Delta) \cdot b}{(b+\Delta) \cdot a}=\frac{a \cdot b+\Delta \cdot b}{a \cdot b+\Delta \cdot a} .
$$

Произведем с данным выражением элементарные математические преобразования и получим, что:

$$
T_{\text {pocma K }}=\frac{K^{\prime}}{K}=\frac{a \cdot b \cdot\left(1+\frac{\Delta}{a}\right)}{a \cdot b \cdot\left(1+\frac{\Delta}{b}\right)} .
$$

\section{Baikal Research Journal}


Таким образом имеем, что темп изменения какого-либо коэффициента $K$ фактически определяется темпами изменения показателей, участвующих в расчете коэффициента за счет осуществленных корректировок:

$$
T_{\text {pocma } K}=\frac{K^{\prime}}{K}=\frac{1+T_{\text {npupocma } a_{\Delta}}}{1+T_{\text {ppupocma }} b_{\Delta}}=\frac{T_{\text {pocma } a_{\Delta}}}{T_{\text {pocma } b_{\Delta}}} .
$$

Отсюда можно сделать вывод, что на изменение соответствующих коэффициентов финансового состояния организации оказывают влияние не столько абсолютные значения корректировок $\Delta$, сколько то обстоятельство, на сколько изменяются сами показатели, участвующие в расчете коэффициента $K$ в относительном выражении (табл. 1 и 2).

Таблица 1

Влияние на значение коэффициента достаточности собственного капитала К организаций $x$ и у корректировок $\triangle$, при различных абсолютных значениях корректировок и одинаковых начальных значениях коэффициента

\begin{tabular}{|c|c|c|c|}
\hline \multirow[t]{2}{*}{ Показатель } & \multirow[t]{2}{*}{ Обозначение / схема расчета } & \multicolumn{2}{|c|}{ Организации } \\
\hline & & $x$ & $y$ \\
\hline$C K$, тыс. p. & A & 30 & 600 \\
\hline BA, тыс. p. & $B$ & 10 & 200 \\
\hline$K$ & $\mathrm{a} / \mathrm{b}$ & 3 & 3 \\
\hline Корректировка $\Delta$ & $\Delta$ & 15 & 150 \\
\hline$K^{\prime}$ & $(a+\Delta) /(b+\Delta)$ & 1,8 & 2,14 \\
\hline Темп роста $K$ & $T_{\text {pocma K }}$ & $\mathbf{0 , 6}$ & $\mathbf{0 , 7 1}$ \\
\hline Темп прироста $C K$ & $T_{\text {npupocma a }}$ & 0,5 & 0,25 \\
\hline Темп прироста $B A$ & $T_{\text {nрupocma } b}$ & 1,5 & 0,75 \\
\hline Темп роста $K$ & $T_{\text {pocma K }}$ & $\mathbf{0 , 6 0}$ & $\mathbf{0 , 7 1}$ \\
\hline Темп роста $C K$ & $T_{\text {pocma a }}$ & 1,5 & 1,25 \\
\hline Темп роста $B A$ & $T_{\text {pocma b }}$ & 2,5 & 1,75 \\
\hline Темп роста $K$ & $T_{\text {pocma K }}$ & 0,60 & $\mathbf{0 , 7 1}$ \\
\hline
\end{tabular}

Таблица 2

Влияние на значение коэффициента достаточности собственного капитала $K$ организаций $x$ и у корректировок $\Delta$, при идентичных относительных значениях корректировок и одинаковых начальных значениях коэффициента

\begin{tabular}{|c|c|c|c|}
\hline \multirow[t]{2}{*}{ Показатель } & \multirow[t]{2}{*}{ Обозначение / схема расчета } & \multicolumn{2}{|c|}{ Организации } \\
\hline & & $x$ & $y$ \\
\hline$C K$, тыс. p. & A & 30 & 600 \\
\hline BA, тыс. p. & $B$ & 10 & 200 \\
\hline K & $\mathrm{a} / \mathrm{b}$ & 3 & 3 \\
\hline Корректировка $\Delta$ & $\Delta$ & 15 & 300 \\
\hline$K^{\prime}$ & $(\mathrm{a}+\Delta) /(b+\Delta)$ & 1,8 & 1,8 \\
\hline Темп роста $K$ & $T_{\text {pocma K }}$ & 0,6 & 0,60 \\
\hline Темп прироста $C K$ & $T_{\text {nрupocma a }}$ & 0,5 & 0,5 \\
\hline Темп прироста $B A$ & $T_{\text {npupocma } b}$ & 1,5 & 1,5 \\
\hline Темп роста $K$ & $T_{\text {pocma K }}$ & $\mathbf{0 , 6 0}$ & 0,60 \\
\hline Темп роста $C K$ & $T_{\text {pocma a }}$ & 1,5 & 1,5 \\
\hline Темп роста $B A$ & $T_{\text {pocma } b}$ & 2,5 & 2,5 \\
\hline Темп роста $K$ & $T_{\text {pocma K }}$ & $\mathbf{0 , 6 0}$ & $\mathbf{0 , 6 0}$ \\
\hline
\end{tabular}

\section{Baikal Research Journal}

электронный научный журнал Байкальского государственного университета 
Вывод о том, что определяющее влияние на изменение финансового коэффициента оказывают темпы изменения показателей, используемых для расчета, а не значение показателя, считаем доказанным. В рассмотренных примерах при одинаковых начальных абсолютных величинах значение коэффициента в первом случае (табл. 1) изменилось у организаций по-разному, а во втором случае (табл. 2) - одинаково.

2. Финансовые коэффициенты, при расчете которых $k-$ темп изменения статьи бухгалтерской отчетности в результате переоценки - мультипликативно присутствует и в числителе, и в знаменателе дроби. В общем виде расчет коэффициентов данной группы после проведения переоценки выглядит следующим образом:

$$
K_{2 \imath p}=\frac{a \cdot k}{b \cdot k} .
$$

Примерами таких показателей является коэффициент амортизации (коэффициент износа) основных средств и дополнительный к нему коэффициент годности основных средств. Очевидно, что проводимая переоценка основных средств не оказывает никакого влияния на размер указанных показателей.

3. Финансовые коэффициенты, при расчете которых $\Delta$ аддитивно присутствует в расчете только в числителе дроби. По данным показателям направления их изменения в результате проведения переоценки очевидно:

- в случае дооценки значение рассчитываемого показателя будет расти;

- в случае уценки значение рассчитываемого показателя будет снижаться.

В общем виде расчет коэффициентов данной группы после проведения трансформационных процедур выглядит следующим образом:

$$
K_{3 \imath p}=\frac{a+\Delta}{b} .
$$

Примерами таких финансовых коэффициентов являются фондооснащенность, фондовооруженность, фондоотдача, коэффициент отношения собственного капитала к заемному.

4. Финансовые коэффициенты, при расчете которых $\Delta$ присутствует только в знаменателе дроби. По данным показателям направления их изменения в результате проведения переоценки также очевидно:

- в случае дооценки значение рассчитываемого показателя будет снижаться;

- в случае уценки значение рассчитываемого показателя будет расти.

В общем виде расчет коэффициентов данной группы после проведения трансформационных процедур выглядит следующим образом:

$$
K_{4 \imath p}=\frac{a}{b+\Delta} .
$$

Примерами таких финансовых коэффициентов являются фондоемкость, коэффициент финансового риска, коэффициент отношения заемного капитала к собственному, рентабельность собственного капитала.

5. В эту группу можно отнести значение абсолютных показателей, при расчете которых используются значения, изменяющиеся в результате проведения переоценки основных средств. Примером таких абсолютных показателей являются чистые активы, наличие у организации собственных оборотных средств. При этом, поскольку при расчете указанных показателей используется и величина собственного капитала, и величина остаточной стоимости основных средств, то значение разности (абсолютного показателя) в результате переоценки не изменится.

По другим важным показателям оценить влияние результатов переоценки на их значение гораздо тяжелее. Например, следует учитывать, что в результате

\section{Baikal Research Journal}

электронный научный журнал Байкальского государственного университета 
произведенной переоценки основных средств в последующие периоды у организации произойдет сдвиг точки безубыточности - одного из важнейших показателей, учитываемых при осуществлении оперативного управления организаций. При этом сдвиг точки безубыточности произойдет независимо от того, к каким затратам - переменным (при начислении амортизации пропорционально объему выпущенной продукции) или постоянным (при начислении амортизации иными методами, когда в качестве основного фактора, оказывающего влияние на размер амортизации, является время) - будет относиться величина начисленной амортизации.

Как известно, в общем случае при производстве одного вида продукции расчет точки безубыточности осуществляется по формуле:

$$
q_{\text {безубыточности }}=\frac{F C}{M R},
$$

где $F C$ - постоянные затраты; $M R$ - маржинальный доход в расчете на 1 ед. продукции.

Используя приведенную формулу (1), значение точки безубыточности до проведения переоценки $\left(q_{0}\right)$ и после проведения переоценки $\left(q_{1}\right)$ можно представить следующим образом:

$$
\begin{aligned}
& q_{0}=\frac{F C_{0}}{M R_{0}}, \\
& q_{1}=\frac{F C_{1}}{M R_{1}} .
\end{aligned}
$$

Пусть амортизация начисляется линейным методом, формируя соответственно постоянные затраты организации. В этом случае $M R_{0}=M R_{1}$. А вот величины постоянных затрат $(F C)$ будут отличаться, поскольку увеличится одна из их составляющих - сумма амортизации. Используя формулы (2) и (3), определим темп роста значения точки безубыточности $\left(T_{q}\right)$ :

$$
T_{q}=\frac{q_{1}}{q_{0}}=\frac{F C_{1}}{F C_{0}} .
$$

При этом размер постоянных затрат очевидно зависит от величины амортизации (A) и доли амортизации в постоянных затратах $(d)$ и составит до проведения переоценки $\left(F C_{0}\right)$ и после проведения переоценки $\left(F C_{1}\right)$ соответственно:

$$
\begin{aligned}
& F C_{0}=\frac{A_{0}}{d_{0}}, \\
& F C_{1}=\frac{A_{1}}{d_{1}} .
\end{aligned}
$$

Подставив формулы (5) и (6) в формулу темпа роста точки безубыточности (4), получаем следующее выражение:

$$
T_{q}=\frac{F C_{1}}{F C_{0}}=\frac{A_{1} \cdot d_{0}}{A_{0} \cdot d_{1}} .
$$

Оценим количественное изменение постоянных затрат после проведения переоценки. Очевидно, что в результате проведения переоценки изменится и величина амортизации $\left(A_{1}\right)$ и ее доля в величине постоянных затрат $\left(d_{1}\right)$. Если предположить, что переоценка производится с коэффициентом $k$ и $\mathrm{S}_{0}-$ перво-

\section{Baikal Research Journal}


начальная стоимость основных средств до проведения переоценки, то получим следующие соотношения:

$$
\begin{gathered}
A_{0}=\frac{S_{0}}{n}, \\
A_{1}=\frac{S_{0} \cdot k}{n} .
\end{gathered}
$$

Подставляя вышеприведенные формулы (8) и (9) в формулу (7), получаем, что темп роста точки безубыточности может быть рассчитан как:

$$
T_{q}=\frac{F C_{1}}{F C_{0}}=\frac{S_{0} \cdot k \cdot n \cdot d_{0}}{n \cdot S_{0} \cdot d_{1}}=\frac{k \cdot d_{0}}{d_{1}} .
$$

Таким образом, темп роста точки безубыточности будет прямо пропорционален коэффициенту переоценки и обратно пропорционален отношению долей амортизации в постоянных затратах (назовем этот показатель мультипликатор доли амортизации в затратах $-M_{d}$ ). Представим данную модель развернуто, расписав в ней расчет доли амортизации в постоянных затратах с использованием величины первоначальной стоимости, срока полезного использования объекта и величины постоянных затрат (известные параметры, используемые при расчете точки безубыточности).

$$
\begin{gathered}
d_{0}=\frac{S_{0}}{n \cdot F C_{0}}, \\
d_{1}=\frac{S_{0} \cdot k}{n \cdot(F C+\Delta A)}=\frac{S_{0} \cdot k}{n \cdot\left(F C_{0}+\frac{S_{0} \cdot k}{n}-\frac{S_{0}}{n}\right)} .
\end{gathered}
$$

Тогда имеем, что мультипликатор доли амортизации в затратах будет равен:

$$
M_{d}=\frac{S_{0} \cdot k \cdot n \cdot F C_{0}}{S_{0} \cdot n\left(F C_{0}+\frac{S_{0} \cdot k}{n}-\frac{S_{0}}{n}\right)}=\frac{k \cdot F C_{0}}{\left(F C_{0}+\frac{S_{0} \cdot k}{n}-\frac{S_{0}}{n}\right)}=\frac{k \cdot F C_{0} \cdot n}{F C_{0} \cdot n+S_{0} \cdot k-S_{0}} .
$$

С использованием полученного значения мультипликатора доли (13) можно получить более простую формулу для определения темпа роста точки безубыточности:

$$
T_{q}=\frac{k \cdot d_{0}}{d_{1}}=\frac{k\left(F C_{0} \cdot n+S_{0} \cdot k-S_{0}\right)}{k \cdot F C_{0} \cdot n}=\frac{F C_{0} \cdot n+S_{0} \cdot k-S_{0}}{F C_{0} \cdot n}=1+\frac{S_{0}(k-1)}{F C_{0} \cdot n} .
$$

Используя формулы (5) и (8) подвергнем данное выражение дальнейшему упрощению и получим:

$$
T_{q}=1+\frac{A_{0}}{F C_{0}}(k-1)=1+d_{0}(k-1) .
$$

При этом очевидно, что поскольку коэффициент переоценки $k>1$, то в результате ее проведения темп роста значения точки безубыточности также будет превышать 1, т. е. порог безубыточности возрастет. Обратная ситуация будет наблюдаться в случае уценки объекта.

Пусть амортизация начисляется методом пропорционально объему выпущенной продукции, формируя соответственно переменные затраты организации.

\section{Baikal Research Journal}


В этом случае $F C_{0}=F C_{1}$. А вот величины переменных затрат и, следовательно, маржинального дохода будут отличаться, поскольку увеличится одна из их составляющих - сумма амортизации. Соответственно имеем, что темп роста значения точки безубыточности $\left(\mathrm{T}_{q}\right)$ составляет:

$$
T_{q}=\frac{q_{1}}{q_{0}}=\frac{F C_{1} \cdot M R_{0}}{M R_{1} \cdot F C_{0}}=\frac{M R_{0}}{M R_{1}} .
$$

При этом маржинальный доход после проведения переоценки уменьшится именно на величину увеличения амортизации в расчете на 1 ед. выпущенной продукции, т. е. при дооценке объекта основных средств порог безубыточности опять-таки увеличится.

Таким образом, при принятии решения о проведении переоценки организации просто необходимо понимать с какими последствиями такого шага она столкнется. При этом в данном исследовании мы затронули лишь верхушку айсберга, рассмотрев влияние переоценки на величину некоторых финансовых показателей. Необходимо понимать, что рассмотренная ситуация может быть подвергнута дальнейшему усложнению, когда будет рассмотрено изменение коэффициентов при переносе величины капитала, сформированного при переоценке основных средств, на величину нераспределенной прибыли, а также влияние на финансовое состояние сумм возникающих постоянных налоговых активов и(или) постоянных налоговых обязательств. Эта тема может являться основой будущих исследований в области управления оценкой бизнеса, стоимостью бизнеса, финансового анализа и финансового менеджмента.

\section{Список использованной литературы}

1. Иванова М. А. Использование интегрального метода для анализа семифакторной мультипликативной модели рентабельности собственного капитала / М. А. Иванова, Е. А. Филатов // Актуальные проблемы права, экономики и управления. - 2014. № 10. - C. 41-44.

2. Мазуренко Т. Я. О факторном анализе рентабельности собственного капитала (на примере СПК Колхоз «Гигант», Оренбургской области) / Т. Я. Мазуренко // Вестник Оренбургского государственного университета. — 2013. — № 8 (157). — С. 226-232.

3. Чупров С. В. Допустимые значения финансовых показателей для обеспечения устойчивости предприятий / С. В. Чупров // Известия Иркутской государственной экономической академии. - 2004. - № 1. - С. 77-81.

4. Абдукаримов И. Т. Изучение состояния и использования собственного капитала предприятия на основе бухгалтерской отчетности / И. Т. Абдукаримов, Л. Г. Абдукаримова // Социально-экономические явления и процессы. - 2013. - № 3 (49). - С. 9-18.

5. Алексеева А. И. Факторный анализ рентабельности собственного капитала организации в условиях кризиса / А. И. Алексеева // Известия Кабардино-Балкарского научного центра РАН. - 2010. - № 2. - С. 5-13.

6. Филатов Е. А. Расчет эффективности работы собственного капитала по методу Филатова / Е. А. Филатов // Известия Иркутской государственной экономической академии. 2008. - № 1. - С. 22-23.

7. Харисова Г. М. Инновационные подходы в анализе эффективности использования собственного капитала компаний нефтегазового комплекса / Г. М. Харисова, И. В. Миронова // Управление экономическими системами. - 2010. — № 24. - С. 372-379.

8. Климова Н. В. Направления совершенствования методики анализа состояния и эффективности использования основных средств / Н. В. Климова // Экономический анализ: теория и практика. - 2008. - № 6. - С. 22-30.

9. Зайцев О. П. Основные средства: обоснование методики комплексного анализа / О. П. Зайцев, Т. В. Жћукова, О. П. Зайцева // Экономический анализ: теория и практика. 2003. - № 2. - C. 52-64.

\section{Baikal Research Journal}


10. Лытнева Н. А. Методика оценки и прогнозирования чистых активов коммерческих предприятий по данным бухгалтерской (финансовой) отчетности / Н. А. Лытнева, Е. А. Кыштымова // Фундаментальные исследования. - 2015. - № 4-0. - С. 218-223.

11. Рукин Б. П. Анализ стоимости чистых активов как инструмент управления устойчивостью организации / Б. П. Рукин, Л. В. Свиридова // Экономический анализ: теория и практика. - 2010. - № 5. - С. 2-6.

12. Глазунов М. И. Концепция собственных оборотных средств / М. И. Глазунов // Экономический анализ: теория и практика. - 2010. - № 11. - С. 61-67.

13. Слободняк И. А. Влияние результатов трансформации на финансовые коэффициенты / И. А. Слободняк, Ю. В. Гильдеева // Международный бухгалтерский учет. — 2013. № 32. - С. 10-18.

\section{References}

1. Ivanova M. A., Filatov E. A.Using integral method for analyzing seven-factorial multiplication model of owner capital profitability. Aktual'nye problemy prava, ekonomiki $i$ upravleniya $=$ Topical Problems of Economics and Law, 2014, no. 10, pp. 41-44. (In Russian).

2. Mazurenko T. Ya. On factorial analysis of owner capital profitability (in terms of APC collective farm "Gigant», Orenburg Oblast). Vestnik Orenburgskogo gosudarstvennogo universiteta $=$ Bulletin of Orenburg State University, 2013, no. 8 (157), pp. 226-232. (In Russian).

3. Chuprov S. V. Feasible set of financial indicators for enterprises' stability. Izvestiya Irkutskoi gosudarstvennoi ekonomicheskoi akademii = Bulletin of Irkutsk State Economics Academy, 2004, no. 1, pp. 77-81. (In Russian).

4. Abdukarimov I. T., Abdukarimova L. G. Investigating state and using company's owner capital on the basis of accounting reports. Sotsial'no-ekonomicheskie yavleniya $i$ protsessy = Socio-Economic Processes and Phenomena, 2013, no. 3 (49), pp. 9-18. (In Russian).

5. Alekseyeva A. I. Factorial analysis of corporate owner capital profitability in terms of crisis. Izvestiya Kabardino-Balkarskogo nauchnogo tsentra RAN = Bulletin of Kabardino-Balgarian Scientific Center of RAS, 2010, no. 2, pp. 5-13. (In Russian).

6. Filatov E. A. Business own capital calculation of work productivity by Filatov method. Izvestiya Irkutskoi gosudarstvennoi ekonomicheskoi akademii = Bulletin of Irkutsk State Economics Academy, 2008, no. 1, pp. 22-23. (In Russian).

7. Kharisova G. M., Mironova I. V. Innovative approaches in analyzing efficiency of using owner capital of oil and gas companies. Upravlenie ehkonomicheskimi sistemami = Management of Economic Systems, 2010, no. 24. pp. 372-379. (In Russian).

8. Klimova N. V. Directions of improving methods of state analysis and efficiency of using fixed assets. Ekonomicheskii analiz: teoriya $i$ praktika = Economic Analysis: Theory and Practice, 2008, no. 6, pp. 22-30. (In Russian).

9. Zaitsev O. P., Zhukova T. V., Zaitseva O. P. Fixed assets: substantiation of complex analysis methods. Ekonomicheskii analiz: teoriya $i$ praktika = Economic Analysis: Theory and Practice, 2003, no. 2, pp. 52-64. (In Russian).

10. Lytneva N. A., Kyshtymova E. A. Methods of assessing and forecasting net assets of commercial enterprises according to accounting (financial) reports. Fundamental'nye issledovaniya = Fundamental Investigations, 2015, no. 4-0, pp. 218-223. (In Russian).

11. Rukin B. P., Sviridova L. V. Analysis of net asset costs as a sustainable management instrument for organizations. Ekonomicheskii analiz: teoriya i praktika = Economic Analysis: Theory and Practice, 2010, no. 5, pp. 2-6. (In Russian).

12. Glazunov M. I. Concept of own current assets. Ekonomicheskii analiz: teoriya i prakti$k a=$ Economic Analysis: Theory and Practice, 2010, no. 11, pp. 61-67. (In Russian).

13. Slobodnyak I. A., Gideyeva Yu. V. Influence of transformation results on financial ratios. Mezhdunarodnyi bukhgalterskii uchet = International Accounting, 2013, no. 32, pp. 10-18. (In Russian).

\section{Информация об авторах}

Слободняк Илья Анатольевич - доктор экономических наук, профессор, кафедра бухгалтерского учета, анализа, статистики и аудита, Байкальский государственный университет, 664003, г. Иркутск, ул. Ленина, 11, e-mail: slob.irk@mail.ru.

\section{Baikal Research Journal}


Алексеев Денис Анатольевич - кандидат экономических наук, доцент, кафедра финансов, Байкальский государственный университет, 664003, г. Иркутск, ул. Ленина, 11, e-mail: denaleks@yandex.ru.

\section{Authors}

Ilya A. Slobodnyak - Doctor habil. (Economics), Professor, Chair of Accounting, Analysis, Statistics and Audit, Baikal State University, 11 Lenin St., 664003, Irkutsk, Russian Federation; e-mail: slob.irk@mail.ru.

Denis A. Alekseyev - PhD in Economics, Associate Professor, Chair of Finance, Baikal State University, 11 Lenin St., 664003, Irkutsk, Russian Federation; e-mail: denaleks@yandex.ru.

\section{Библиографическое описание статьи}

Слободняк И. А. Влияние результатов переоценки основных средств на величину финансовых коэффициентов / И. А. Слободняк, Д. А. Алексеев // Baikal Research Journal. — 2017. - T. 8, № 1. — DOI: 10.17150/2411-6262.2017.8(1).1.

\section{Reference to article}

Slobodnyak I. A., Alekseyev D. A. Influence of results of revaluating fixed assets by value of financial ratios. Baikal Research Journal, 2017, vol. 8, no. 1. DOI: 10.17150/24116262.2017.8(1).1. (In Russian).

\section{Baikal Research Journal}

